\title{
AVALIAÇÃO DA BIODEGRADAÇÃO DE SERRAGEM DE REBAIXAMENTO DE COURO CURTIDO AO CROMO
}

\author{
K. H. BERWIG ${ }^{1}$, J. PESSUTO ${ }^{1}$ e A. DETTMER ${ }^{1}$ \\ ${ }^{1}$ Universidade de Caxias do Sul, Laboratório de Energia e Bioprocessos \\ E-mail para contato: karinaberwig@gmail.com.br
}

\begin{abstract}
RESUMO - O setor de curtumes gera grandes quantidades de resíduos em seu processo, sendo que apenas $30-35 \%$ da matéria-prima é convertida em couro. O presente trabalho avaliou o processo de biodegradação como alternativa para o tratamento de resíduos de couro curtido ao cromo, além de analisar a influência de um pré-tratamento. Utilizou-se estrume suíno e lodo de estação de tratamento de efluentes de curtume (ETE) como fonte de microrganismos (meios de degradação). O resíduo de couro foi caracterizado por meio de análises de teor de umidade, sólidos totais, carbono orgânico (CO), nitrogênio Kjeldahl total (NTK), cromo e microscopia eletrônica de varredura (MEV). Estes resíduos foram adicionados a frascos de vidro com os meios de degradação e pré-tratamento e então acondicionados em banho termostático a $35^{\circ} \mathrm{C}$, por 19 dias. Após este período, as amostras foram analisadas quanto à concentração de CO, NTK, cromo e MEV. Verificou-se que a melhor condição de biodegradação é a realização de pré-tratamento e a utilização de lodo de ETE de curtume, que proporcionou uma redução da concentração de CO na amostra de aproximadamente 21,44\%.
\end{abstract}

\section{INTRODUÇÃO}

O gerenciamento adequado dos resíduos urbanos e principalmente industriais gera grande preocupação atualmente. Inúmeros estudos são realizados com o objetivo de otimizar não só o tratamento dos resíduos como também os processos por meio dos quais estes são gerados. A indústria brasileira do couro possui grande participação mundial, sendo o Rio Grande do Sul um dos estados com maior contribuição no amplo volume de exportações.

Além da problemática da quantidade, tanto os resíduos sólidos quanto os líquidos possuem alta periculosidade. Boa parte destes é considerada resíduo classe I (perigoso) pela Norma Brasileira de Referência (NBR) 10.004:2004, da Associação Brasileira de Normas Técnicas (ABNT) (2004). O agente mais utilizado no processo de curtimento das peles contém cromo trivalente, sendo este uma das principais razões para a classificação dos resíduos como perigosos (Guterres, 2008). O cromo trivalente não apresenta efeitos tóxicos, porém, a problemática reside na lixiviação e posterior oxidação deste elemento para hexavalente, que é extremamente nocivo à saúde humana (Kolomaznik et al., 2008).

Os resíduos considerados classe I devem ser tratados de maneira adequada ou ainda dispostos em aterros para resíduos industriais perigosos, porém, muitos tratamentos possuem custo elevado e geram novos resíduos, tornando a disposição em aterros a escolha majoritária das indústrias devido ao baixo investimento. Porém, a disposição nestes os torna muito 
inativos em consequência do curtimento, que torna as peles resistentes à degradação microbiológica (Dhayalan et al., 2007).

A digestão anaeróbia, processo que deve ocorrer naturalmente nos aterros, é responsável pela degradação do material orgânico, produzindo, entre outras substâncias, biogás (Covington et al., 2003; Dhayalan et al., 2007). O processo de biodegradação pode ser otimizado por meio do controle de condições como a relação carbono/nitrogênio $(\mathrm{C} / \mathrm{N}), \mathrm{pH}$, temperatura, concentração de sólidos totais, inóculo, e ainda a realização de pré-tratamentos no material a ser biodegradado.

De acordo com Raposo et al. (2011), os substratos e meios utilizados devem ser analisados quanto à umidade e concentração de sólidos totais, afirmando que para bons resultados esta última não deve ultrapassar a concentração de $10 \%$. A relação $\mathrm{C} / \mathrm{N}$ também possui influência sobre a biodegradação, sendo que o valor ótimo para este parâmetro encontra-se entre 20 e 30 (Inoue, 2008). Ainda, o lodo obtido na ETE de um curtume pode ser utilizado como inóculo, pois apresenta microrganismos que podem sobreviver na presença de metais pesados. Sabendo que o couro curtido é dotado de alta estabilidade, podem ser realizados pré-tratamentos para que este se torne mais suscetível à degradação biológica, tornando a digestão anaeróbia uma solução para a gestão dos resíduos e também uma potencial fonte de combustível (Siddique et al., 2014).

Este trabalho possui o objetivo de avaliar o processo de biodegradação da serragem de rebaixamento de couro curtido ao cromo, bem como a influência da realização de um prétratamento e da utilização de meios de degradação. Com a finalidade de determinar a melhor condição de biodegradação pretende-se avaliar parâmetros como umidade, sólidos totais, morfologia, NTK, concentração de cromo e CO.

\section{MATERIAIS E MÉTODOS}

\subsection{Caracterização dos resíduos}

O resíduo de serragem de rebaixamento de couro e o lodo de ETE utilizados foram fornecidos pela empresa Peles Pampa, localizada no município de Portão, no estado do Rio Grande do Sul (RS). O estrume suíno foi obtido em uma propriedade rural localizada no município de Ibirubá, RS.

Os resíduos e suas combinações (amostras) utilizadas para os ensaios de biodegradação foram caracterizados antes e após os experimentos, por meio das análises de determinação de umidade e sólidos totais (ASTM D3790-12), NTK (ASTM D2868-10), espectrometria de absorção atômica para determinação de cromo (Eaton et al., 2012) e CO por meio da metodologia de Tedesco et al. (2005). Ainda, a amostra que apresentou o melhor resultado de redução de carbono orgânico foi previamente seca por meio de imersão em acetona (Guterres, 2008) e após analisada quanto à morfologia por meio de MEV, realizada em equipamento da marca Shimadzu modelo Superscan SS-500, com recobrimento das amostras com ouro. Todos os ensaios de caracterização foram realizados em triplicata. 


\subsection{Procedimento experimental}

Os ensaios de biodegradação anaeróbia foram realizados em duplicata dispondo-se os resíduos em frascos de vidro com volume de $100 \mathrm{~mL}$ e bocal de $2 \mathrm{~mm}$. Estes foram fechados em tampas de borracha e vedados com lacres de alumínio para garantir o isolamento. Após o acondicionamento dos resíduos nos frascos, estes foram rotulados e a estes designados números de amostra. A Tabela 1 apresenta a relação das amostras utilizadas nos ensaios realizados.

Tabela 1- Amostras utilizadas para os ensaios de biodegradação

\begin{tabular}{|c|c|c|c|}
\hline Amostra & Composição & Amostra & Composição \\
\hline 1 & Estrume suíno & 8 & Resíduo de couro e lodo de ETE \\
\hline 2 & Estrume suíno e solução tampão & 9 & Resíduo de couro com pré-tratamento \\
\hline 3 & Lodo de ETE & 10 & $\begin{array}{l}\text { Resíduo de couro com pré-tratamento e } \\
\text { solução tampão }\end{array}$ \\
\hline 4 & Resíduo de couro & 11 & $\begin{array}{c}\text { Resíduo de couro com pré-tratamento e } \\
\text { estrume suíno }\end{array}$ \\
\hline 5 & $\begin{array}{l}\text { Resíduo de couro e solução } \\
\text { tampão }\end{array}$ & 12 & $\begin{array}{l}\text { Resíduo de couro com pré-tratamento, } \\
\text { estrume suíno e solução tampão }\end{array}$ \\
\hline 6 & Resíduo de couro e estrume suíno & 13 & $\begin{array}{l}\text { Resíduo de couro com pré-tratamento e } \\
\text { lodo de ETE }\end{array}$ \\
\hline 7 & $\begin{array}{l}\text { Resíduo de couro, estrume suíno } \\
\text { e solução tampão }\end{array}$ & & \\
\hline
\end{tabular}

A massa de resíduo de couro utilizada foi $0,15 \mathrm{~g}$ (base seca) e a de estrume suíno foi $3 \mathrm{~g}$ (base seca), que foram determinadas com o objetivo de manter a melhor razão $\mathrm{C} / \mathrm{N}$ possível, aobtida foi de 7,3. O volume de lodo de curtume foi determinado conforme o experimento de Covington et al. (2003), utilizou-se 7,5 mL de lodo de ETE para 0,15 g de resíduo de couro. O pré-tratamento foi adaptado da metodologia utilizada por Dhayalan et al. (2007), utilizando 200\% de água destilada, 0,003 g de ácido oxálico e 0,003 g de ácido etilenodiamino tetraacético (EDTA). A solução tampão foi produzida a partir de soluções de fosfato de potássio monobásico $0,1 \mathrm{~mol} / \mathrm{L}$ e de hidróxido de potássio $0,2 \mathrm{~mol} / \mathrm{L}$, de maneira a manter seu $\mathrm{pH}$ em torno de 7. A solução tampão foi adicionada a cada frasco de maneira a manter o teor de sólidos totais em torno de $9 \%$. As amostras foram acondicionadas em banho termostático, à temperatura de $35^{\circ} \mathrm{C}$.A determinação do tempo de ensaio deu-se por meio de medições do gás produzido, assim, quando não houve mais produção de gás, as amostras foram retiradas do banho. O tempo de ensaio foi de 19 dias.

\section{RESULTADOS E DISCUSSÃO}

\subsection{Caracterização dos resíduos}

Com o objetivo de verificar se o processo utilizado para a biodegradação dos resíduos foi eficaz, estes foram caracterizados. A Tabela 2 apresenta os resultados obtidos.

Parâmetro

Umidade (\%)
Tabela 2 - Caracterização dos resíduos

$\begin{array}{cc}\text { Resíduo de couro } & \text { Estrume suíno } \\ 53,23 & 73,02\end{array}$
73,02 
Sólidos totais $(\%)$

CO* $(\%)$

NTK* $(\%)$

Cromo total* $(\%)$
46,77

35,49

13,00

2,39

* Dados obtidos em base seca.
26,07

1,47

41,16

27,90

1,23

4,21

Os resultados obtidos para a caracterização do resíduo de couro encontram-se próximos a valores encontrados por outros autores (Kipper, 2013; Piccin et al., 2012). A razão C/N é baixa, o que confirma a necessidade de adição de meios que aumentem o valor deste parâmetro visando melhorar o processo de degradação. O estrume suíno apresentou resultados de CO e NTK que coincidem com os obtidos por outros autores (Hsu e Lo, 2001; Tsai et al., 2012), contudo, o teor de sólidos totais e de umidade são divergentes. A composição do estrume suíno pode variar conforme inúmeros fatores, como a alimentação dos animais, condições de coleta, períodos de armazenamento, entre outros. No caso do lodo de ETE os valores de CO e NTK são aproximados aos obtidos por outros autores, como Haroun et al. (2009). Os teores de cromo encontrados na literatura são de grande divergência, que pode ocorrer de acordo com as etapas realizadas no processamento do curtume.

\subsection{Caracterização das amostras após os ensaios de biodegradação}

Concentração de CO: A Tabela 3 apresenta as concentrações de CO das amostras antes e após a realização dos ensaios. Nota-se a diminuição da concentração de CO nas amostras 3 , 12, 13. Em seus experimentos de biodegradação de resíduos de couro, Dhayalan et al. (2007) também relataram a diminuição da concentração deste parâmetro.

Tabela 3 - Concentrações de carbono orgânico em base seca

$\begin{array}{cccccc}\text { Amostra } & \begin{array}{c}\text { Concentração } \\ \text { inicial (\%) }\end{array} & \begin{array}{c}\text { Concentração } \\ \text { final (\%) }\end{array} & \begin{array}{c}\text { Amostra } \\ \mathbf{1}\end{array} & \begin{array}{c}\text { Concentração } \\ \text { inicial (\%) }\end{array} & \begin{array}{c}\text { Concentração } \\ \text { final (\%) }\end{array} \\ \mathbf{1} & 41,16 & 42,37 & \mathbf{8} & 32,28 & 31,98 \\ \mathbf{3} & 41,16 & 42,07 & \mathbf{9} & 34,12 & 34,74 \\ \mathbf{4} & 27,90 & 12,92 & \mathbf{1 0} & 34,12 & 31,97 \\ \mathbf{5} & 35,49 & 34,26 & \mathbf{1 1} & 40,81 & 40,53 \\ \mathbf{6} & 35,49 & 33,84 & \mathbf{1 2} & 40,81 & 38,47 \\ \mathbf{7} & 40,89 & 40,48 & \mathbf{1 3} & 32,28 & 25,36 \\ & 40,89 & 39,64 & & & \end{array}$

Nota: 1 - Estrume suíno; 2 - Estrume suíno e solução tampão; 3 - Lodo de ETE; 4 -

Resíduo de couro; 5 - Resíduo de couro e solução tampão; 6 - Resíduo de couro e estrume suíno; 7 - Resíduo de couro, estrume suíno e solução tampão; 8 - Resíduo de couro e lodo de ETE; 9 - Resíduo de couro com pré-tratamento; 10 - Resíduo de couro com pré-tratamento e solução tampão; 11 - Resíduo de couro com pré-tratamento e estrume suíno; 12 - Resíduo de couro com pré-tratamento, estrume suíno e solução tampão; 13 - Resíduo de couro com prétratamento e lodo de ETE.

As amostras contendo solução tampão $(5,7,10,12)$ sofreram maior redução na concentração de carbono orgânico em comparação às amostras de mesma composição, porém sem esta solução $(4,6,9,11)$. O controle de $\mathrm{pH}$, menor concentração de sólidos totais e melhor interação entre os sólidos proporcionados pela adição da solução tampão acarretam em um melhor processo de biodegradação dos compostos. As amostras contendo resíduo de 
couro pré-tratado $(9,10,11,12,13)$ e ainda com solução tampão ou lodo de ETE apresentaram melhor desempenho do que as amostras de resíduo de couro $(4,5,6,7,8)$. Além do controle de $\mathrm{pH}$ (solução tampão) e redução do teor de sólidos (solução tampão e lodo de ETE), ocorre também a desestabilização causada na estrutura do couro, ocasionada pelo prétratamento. Ainda, o lodo de ETE possui microrganismos adaptados a condições severas (exposição ao cromo e variação de pH).

Verifica-se ainda que a adição de estrume suíno às amostras de resíduo de couro não possuiu influência positiva, resultando em reduções menores do teor de carbono orgânico. Pode-se inferir que a toxicidade do curtimento prejudicou os microrganismos existentes no estrume suíno e, consequentemente, o processo de digestão anaeróbia. A amostra de lodo de ETE (3) apresentou alta redução da concentração de carbono. As amostras de resíduo de couro e lodo de ETE (13) também apresentaram redução, destacando-se a amostra de couro pré-tratado e lodo de ETE, indicando a ocorrência de biodegradação na amostra. Por meio da análise de variância da variação entre a concentração final e a inicial observou-se que apenas as amostras 3 e 13 apresentaram redução significativa de concentração de carbono orgânico. Para as amostras que apresentaram concentração de $\mathrm{CO}$ final maior que o inicial considerouse a variação igual a zero.

Concentração de NTK: A Tabela 4 apresenta os resultados obtidos para as concentrações de NTK presentes nas amostras antes e após os ensaios.

Tabela 4 - Concentração de nitrogênio em base seca

$\begin{array}{cccccc}\text { Amostra } & \begin{array}{c}\text { Concentração } \\ \text { inicial (\%) }\end{array} & \begin{array}{c}\text { Concentração } \\ \text { final (\%) }\end{array} & \begin{array}{c}\text { Amostra } \\ \text { Concentração } \\ \text { inicial (\%) }\end{array} & \begin{array}{c}\text { Concentração } \\ \text { final (\%) }\end{array} \\ \mathbf{1} & 2,41 & 1,68 & \mathbf{8} & 8,02 & 11,74 \\ \mathbf{2} & 2,41 & 1,37 & \mathbf{9} & 12,50 & 14,32 \\ \mathbf{3} & 1,23 & 1,19 & \mathbf{1 0} & 12,50 & 13,81 \\ \mathbf{4} & 13,00 & 14,35 & \mathbf{1 1} & 2,91 & 2,44 \\ \mathbf{5} & 13,00 & 13,98 & \mathbf{1 2} & 2,91 & 3,41 \\ \mathbf{6} & 2,91 & 2,93 & \mathbf{1 3} & 8,02 & 9,29 \\ \mathbf{7} & 2,91 & 3,13 & & & \end{array}$

Nota: 1 - Estrume suíno; 2 - Estrume suíno e solução tampão; 3 - Lodo de ETE; 4 -

Resíduo de couro; 5 - Resíduo de couro e solução tampão; 6 - Resíduo de couro e estrume suíno; 7 - Resíduo de couro, estrume suíno e solução tampão; 8 - Resíduo de couro e lodo de ETE; 9 - Resíduo de couro com pré-tratamento; 10 - Resíduo de couro com pré-tratamento e solução tampão; 11 - Resíduo de couro com pré-tratamento e estrume suíno; 12 - Resíduo de couro com pré-tratamento, estrume suíno e solução tampão; 13 - Resíduo de couro com prétratamento e lodo de ETE.

Observou-se que apenas as amostras 1, 2 e 11 apresentaram redução das concentrações de NTK. Através da análise de variância da variação de concentração de NTK concluiu-se que a amostra 2 possui a maior redução quando comparada as amostras 1 e 11 . Para as amostras que apresentaram concentração de NTK final maior que o inicial considerou-se a variação igual a zero.

Para as demais os valores de nitrogênio não sofreram variações, isto pode ser atribuído ao curto tempo de biodegradação utilizado neste trabalho, 19 dias. Kipper (2013) realizou 
experimentos de biodegradação de resíduos de couro curtido ao cromo e lodo biológico de ETE de curtume, utilizando tratamentos enzimáticos. O autor observou que a concentração de NTK sofre redução devido ao processo de digestão anaeróbia após longos períodos de biodegradação (120 dias).

Concentração de cromo: A Tabela 5 apresenta as concentrações de cromo nas amostras antes e após os ensaios de biodegradação. Verifica-se o aumento da concentração de cromo em grande parte das amostras, indicando a ocorrência de perda de massa que implica neste aumento de concentração, ratificando os resultados referentes às concentrações de carbono orgânico.

Tabela 5 - Concentração de cromo em base seca

\begin{tabular}{|c|c|c|c|c|c|}
\hline Amostra & $\begin{array}{c}\text { Concentração } \\
\text { inicial }(\%)\end{array}$ & $\begin{array}{c}\text { Concentração } \\
\text { final }(\%)\end{array}$ & Amostra & $\begin{array}{c}\text { Concentração } \\
\text { inicial (\%) }\end{array}$ & $\begin{array}{c}\text { Concentraçãa } \\
\text { final }(\%)\end{array}$ \\
\hline 1 & 0 & 0 & 8 & 3,16 & 2,81 \\
\hline 2 & 0 & 0 & 9 & 2,30 & 2,85 \\
\hline 3 & - & - & 10 & 2,30 & 2,43 \\
\hline 4 & 2,39 & 2,88 & 11 & 0,11 & 0,13 \\
\hline 5 & 2,39 & 3,01 & 12 & 0,11 & 0,13 \\
\hline 6 & 0,11 & 0,13 & 13 & 3,16 & 3,38 \\
\hline 7 & 0,11 & 0,14 & & & \\
\hline
\end{tabular}

Nota: 1 - Estrume suíno; 2 - Estrume suíno e solução tampão; 3 - Lodo de ETE; 4 -

Resíduo de couro; 5 - Resíduo de couro e solução tampão; 6 - Resíduo de couro e estrume suíno; 7 - Resíduo de couro, estrume suíno e solução tampão; 8 - Resíduo de couro e lodo de ETE; 9 - Resíduo de couro com pré-tratamento; 10 - Resíduo de couro com pré-tratamento e solução tampão; 11 - Resíduo de couro com pré-tratamento e estrume suíno; 12 - Resíduo de couro com pré-tratamento, estrume suíno e solução tampão; 13 - Resíduo de couro com prétratamento e lodo de ETE.

A amostra contendo resíduo de couro e solução tampão (5) obteve maior aumento da concentração do que a amostra contendo apenas resíduo de couro (4). Da mesma forma a amostra contendo couro, estrume suíno e solução tampão (7) apresentou maior concentração final em comparação à amostra que não continha esta solução (6).

A amostra contendo couro e lodo de ETE (8) apresentou mínima redução da concentração. Levando-se em conta o erro experimental, considera-se que a concentração de cromo permaneceu a mesma. Este resultado concorda com os valores obtidos para a concentração de carbono, que também sofreram mínima redução. A amostra 13 (resíduo de couro pré-tratado e lodo de ETE) apresentou aumento da concentração de cromo após o ensaio, o que indica a ocorrência de biodegradação do resíduo e consequente aumento da concentração.

MEV: Realizou-se MEV do resíduo de couro antes e após o processo de biodegradação, da amostra com pré-tratamento e lodo de ETE, a qual, por meio das análises de $\mathrm{CO}$ e de cromo, julgou-se ser a melhor condição de biodegradação. A Figura 1 apresenta as imagens de MEV obtidas. Por meio desta, verifica-se que o resíduo é constituído de uma rede de fibras. Ainda é possível observar que após o processo de biodegradação estas se encontram mais esparsas, desordenadas e eriçadas, indicando que a adesão entre estas diminuiu. 

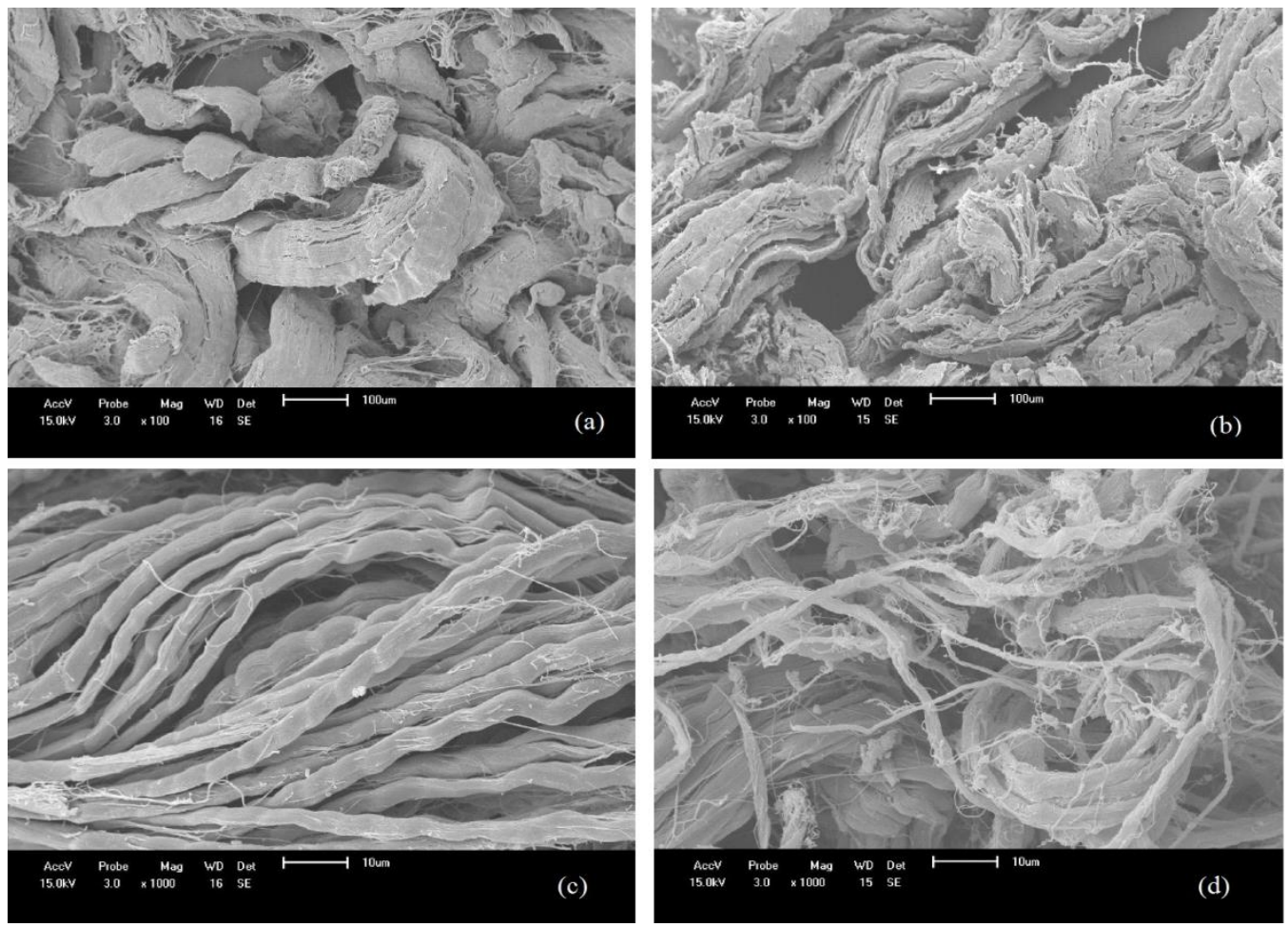

Figura 1 - Imagens de MEV obtidas para o resíduo de couro antes (a, c) e após (b, d) a biodegradação, magnificação original de 100x (a,b) e 1000x (c,d).

\section{CONCLUSÃO}

O desempenho das amostras com a adição de solução tampão foi superior às de mesma composição, porém sem a solução, evidenciando que o controle de $\mathrm{pH}$, a redução do teor de sólidos totais e a interação proporcionada entre os sólidos são essenciais para o processo de biodegradação.

A utilização de lodo de ETE como meio de degradação produziu os melhores resultados, destacando-se quando utilizado com a amostra de couro pré-tratado. Confirmou-se que o meio líquido proporciona maior mobilidade aos microrganismos e que estes presentes no lodo de curtume são resistentes ao metal contido no resíduo.

O pré-tratamento realizado também possuiu influência positiva no processo por ser capaz de reverter a ligação gerada por meio do curtimento das peles. A adição de estrume suíno aos resíduos de couro não apresentou influência considerável na biodegradação destes, confirmando que a ligação entre a pele e o curtente do resíduo de couro curtido deve ser desestabilizada. Ainda, por meio das imagens de MEV verificou-se que a estrutura do resíduo de couro sofreu modificações, indicando a degradação.

\section{AGRADECIMENTOS}

Este trabalho foi financiado pela Fundação de Amparo à Pesquisa no Rio Grande do Sul (FAPERGS). 


\section{REFERÊNCIAS}

ASSOCIAÇÃO BRASILEIRA DE NORMAS TÉCNICAS. NBR 10.004: Resíduos sólidos Classificação. Rio de Janeiro, 2004.

AMERICAN SOCIETY FOR TESTING AND MATERIALS. ASTM D2868:Standard Test Method for Nitrogen Content (Kjeldahl) and Hide Substance Content of Leather. 2010. ASTM D3790: Standard Test Method for Volatile Matter (Moisture) of Leather by Oven Drying. 2012.

COVINGTON, A. D.; PAUL, R. G.; YAGOUB, S. Biodegradation of solid leather wastes. Cuoio Pelli Mat. Conc., v. 79, p. 187-196, 2003.

DHAYALAN, K.; FATHIMA, N. N.; GNANAMANI, A.; RAO, R. J.; NAIR, B. U.; RAMASAMI, T. Biodegradability of leathers through anaerobic pathway. Waste Manag., v. 27, p. 760-767, 2007.

EATON, A. D.; RICE, E. W.; BAIRD, R. B.; CLESCERI, A. D. Standard Methods for the Examination of Water and Wastewater. Denver: Ed. Amer. Public Health Assn., 2012.

GUTTERRES, M. A ciência rumo à tecnologia do couro. Porto Alegre: Editora Tríplice Assessoria e Soluções Ambientais, 2008.

HAROUN, M.; IDRIS, A.; OMAR, S. Analysis of heavy metals during composting of the tannery sludge using physicochemical and spectroscopic techniques. J. Hazard. Mat., v. 165, p. 111-119, 2009.

HSU, J. H.; LO, S. L. Effect of composting on characterization and leaching of copper, manganese, and zinc from swine manure. Environ. Pollution, v. 114, p. 119-127, 2001.

INOUE, K.R.A. Produção de biogás, caracterização e aproveitamento agrícola do biofertilizante obtido na digestão da manipueira. 92 f. Programa de Pós-Graduação em Engenharia Agrícola, Universidade Federal de Viçosa, 2008.

KIPPER, E. Tratamento enzimático e produção de biogás por resíduos sólidos de curtume. 112 f. Programa de Pós-Graduação em Engenharia Química, Universidade Federal do Rio Grande do Sul, 2013.

KOLOMAZNIK, K.; ADAMEK, M.; ANDEL, I.; UHLIROVA, M. Leather waste - Potential threat to human health, and a new technology of its treatment. J. Hazard. Mat., v. 160, p. 514-520, 2008.

PICCIN, J. S.; GOMES, C. S.; FERIS, L.A.; GUTTERRES, M. Kinetics and isotherms of leather dye adsorption by tannery solid waste. Chem. Eng. J., v. 183, p. 30-38, 2012.

RAPOSO, F.; DE LA RUBIA, M. A.; FERNÁNDEZ-CEGRÍ, V.; BORJA, R. Anaerobic digestion of solid organic substrates in batch mode: An overview relating to methane yields and experimental procedures. Renew. and Sust. Energy Reviews, v. 16, p. 861$877,2011$.

SIDDIQUE, N. I.; MUNAIM, M. S. A.; ZULARISAM, A. W. Hemophilic and thermophilic biomethane production by co-digesting pretreated petrochemical wastewater with beef and dairy cattle manure. J. Ind. Eng. Chem., v. 20, p. 331-337, 2014.

TEDESCO, M. J.; GIANELLO, C.; BISSANI, C. A.; BOHNEN, H.; VOLKWEISS, S. J. Análises de solo, plantas e outros materiais. Porto Alegre: Editora UFRGS, 2005.

TSAI, W. T.; LIU, S. C.; CHEN, H. R.; CHANG, Y. M.; TSAI, Y. L. Textural and chemical properties of swine-manure-derived biochar pertinent to its potential use as a soil amendment. Chemosphere, v. 89, p. 198-203, 2012. 